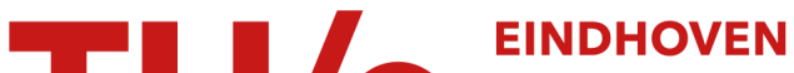 \\ UNIVERSITY OF \\ TECHNOLOGY
}

\section{On high-frequency circuit equivalents of a vertical ground rod}

Citation for published version (APA):

Grcev, L., \& Popov, M. (2005). On high-frequency circuit equivalents of a vertical ground rod. IEEE Transactions on Power Delivery, 20(2), 1598-1603. https://doi.org/10.1109/TPWRD.2004.838460

DOI:

10.1109/TPWRD.2004.838460

Document status and date:

Published: 01/01/2005

\section{Document Version:}

Publisher's PDF, also known as Version of Record (includes final page, issue and volume numbers)

\section{Please check the document version of this publication:}

- A submitted manuscript is the version of the article upon submission and before peer-review. There can be important differences between the submitted version and the official published version of record. People interested in the research are advised to contact the author for the final version of the publication, or visit the $\mathrm{DOI}$ to the publisher's website.

- The final author version and the galley proof are versions of the publication after peer review.

- The final published version features the final layout of the paper including the volume, issue and page numbers.

Link to publication

\section{General rights}

Copyright and moral rights for the publications made accessible in the public portal are retained by the authors and/or other copyright owners and it is a condition of accessing publications that users recognise and abide by the legal requirements associated with these rights.

- Users may download and print one copy of any publication from the public portal for the purpose of private study or research.

- You may not further distribute the material or use it for any profit-making activity or commercial gain

- You may freely distribute the URL identifying the publication in the public portal.

If the publication is distributed under the terms of Article $25 \mathrm{fa}$ of the Dutch Copyright Act, indicated by the "Taverne" license above, please follow below link for the End User Agreement:

www.tue.nl/taverne

Take down policy

If you believe that this document breaches copyright please contact us at:

openaccess@tue.nl

providing details and we will investigate your claim. 


\title{
On High-Frequency Circuit Equivalents of a Vertical Ground Rod
}

\author{
Leonid Grcev, Senior Member, IEEE, and Marjan Popov, Senior Member, IEEE
}

\begin{abstract}
Vertical ground rods have been used extensively from the early days of electrical engineering for earth termination of electrical and lightning protection systems. They are usually represented with equivalent circuits with lumped and distributed parameters based on quasistatic approximation, which limits the upper frequency of their validity domain. However, lightning-related studies often require modeling in the megahertz frequency range. Also, emerging technologies, such as power-line communications, require analysis in frequency ranges even up to a few tens of megahertz. The rigorous electromagnetic (EM) field theory approach may be used for such frequency ranges, but equivalent circuits are needed for the usual network analysis methods. In this paper, we look at possibilities to construct simple equivalent circuits that can approximate or match results from the EM model. In particular, we compare a usual homogenous distributed parameter circuit with a nonhomogenous one determined by curve matching with results from the EM model. The analysis is illustrated using numerical simulations.
\end{abstract}

Index Terms-Distributed parameter circuits, electromagnetic (EM) analysis, equivalent circuits, grounding electrodes, modeling, transient analysis.

\section{INTRODUCTION}

$\mathbf{V}$ ERTICAL ground rods are one of the simplest and most commonly used means for earth termination of electrical and lightning protection systems [1]. Their behavior at 50 or $60 \mathrm{~Hz}$ is well understood using a simplified analysis based on static approximation [2]. However, their high-frequency and transient performance is also of interest when, for example, they are subjected to lightning or other high-frequency excitations considered in electromagnetic-compatibility (EMC) studies or in telecommunications [3], [4]. The property that is of primary interest is their input impedance or impedance to remote neutral ground. Traditionally at low frequencies, this impedance is represented by a single resistor Fig. 1(b) and at high frequencies by a lumped R-L-C circuit Fig. 1(c) [5]. Two sets of formulas for the parameters of the R-L-C circuit are often used. One is from the reference work by Rudenberg [5]

$$
\begin{aligned}
R & =\frac{\rho}{2 \pi \ell} \log \frac{2 \ell}{a}(\Omega) \\
C & =2 \pi \varepsilon \ell\left(\log \frac{2 \ell}{a}\right)^{-1} \\
L & =\frac{\mu_{0} \ell}{2 \pi} \log \frac{2 \ell}{a}(\mathrm{H})
\end{aligned}
$$

Manuscript received July 28, 2003; revised October 8, 2003. Paper no. TPWRD-00395-2003.

L. Grcev was with the Department of Electrical Engineering, Eindhoven University of Technology, Eindhoven $5600 \mathrm{MB}$, The Netherlands. He is now with the Faculty of Electrical Engineering, St. Cyril and Methodius University, Skopje 1000, Macedonia (e-mail: leonid.grcev@ieee.org).

M. Popov is with the Power Systems Laboratory, Delft University of Technology, Delft 2628CD, The Netherlands (e-mail: M.Popov@ieee.org).

Digital Object Identifier 10.1109/TPWRD.2004.838460

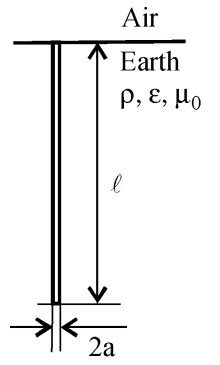

(a)

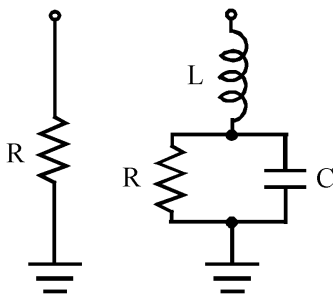

(b)

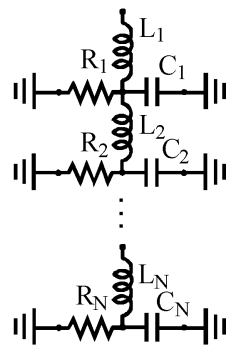

(d)
Fig. 1. Low-current models of a vertical ground rod. (a) Physical situation. (b) Low-frequency equivalent circuit. (c) High-frequency lumped R-L-C circuit. (d) High-frequency distributed parameters circuit.

and the other is [6], [7], [9]

$$
\begin{aligned}
R & =\frac{\rho}{2 \pi \ell}\left[\log \frac{4 \ell}{a}-1\right](\Omega) \\
C & =2 \pi \varepsilon \ell\left[\log \frac{4 \ell}{a}-1\right](\mathrm{F}) \\
L & =\frac{\mu_{0} \ell}{2 \pi}\left[\log \frac{2 \ell}{a}-1\right](\mathrm{H}) .
\end{aligned}
$$

Here, symbols are given in Fig. 1(a), and $\ell \gg a$. Although the results from (1) are somewhat larger than those from (2), both sets of formulas lead to similar results for the impedance to ground. In this paper, we use (2) since it leads to a better match with the EM model.

Parameters of the R-L-C circuit, (1) and (2), are also used in a distributed-parameter circuit [6], [7]

$$
R^{\prime}=\frac{1}{G^{\prime}}=R \ell(\Omega \mathrm{m}) ; \quad C^{\prime}=\frac{C}{\ell}(\mathrm{F} / \mathrm{m}) ; \quad L^{\prime}=\frac{L}{\ell}(\mathrm{H} / \mathrm{m}) \text {. }
$$

The transmission line may be considered as open at the lower end, and the input impedance (equivalent to the harmonic impedance to ground) is [7]

$$
\begin{aligned}
Z & =Z_{0} \operatorname{coth} \gamma \ell \\
Z_{0} & =\sqrt{\frac{j \omega L^{\prime}}{\left(G^{\prime}+j \omega C^{\prime}\right)}} \\
\gamma & =\sqrt{j \omega L^{\prime}\left(G^{\prime}+j \omega C^{\prime}\right)} .
\end{aligned}
$$

A discrete approximation of the distributed-parameter circuit is often used, for example, in [15]. The rod is divided into $N$ fictitious segments and each segment of the rod is represented by a R-L-C section [Fig. 1(d)]. Identical parameters are used for each section

$$
R_{n}=\frac{R^{\prime} N}{\ell} ; \quad C_{n}=\frac{C^{\prime} \ell}{N} ; \quad L_{n}=\frac{L^{\prime} \ell}{N}, \quad n=1,2, \ldots, N
$$

where $R^{\prime}, L^{\prime}$, and $C^{\prime}$ are given in (3). 
The models in Fig. 1(c) and (1d) are so-called "low current" models, but they have been also used as nonlinear "high current" models by simply replacing the constant resistors in the circuits with the nonlinear time-dependent resistor [8], [15]. In case of lightning, the electric field at the rod may become larger than the electric strength of the ground, resulting in breakdown and sparks discharge. This may greatly improve the grounding performance of the rod, especially in less conductive soil. In such a case, the ground rod resistance to ground may be approximately represented by a resistor with a nonlinear resistance as a function of current through the rod [8]

$$
R(t)=\frac{R}{\sqrt{\frac{1+i(t)}{I_{g}}}} ; \quad I_{g}=\frac{E_{0} \rho}{2 \pi R^{2}} .
$$

Here, $i(t)$ is the current through the rod, $E_{0}$ is the soil critical electric field intensity (approximately $300 \mathrm{kV} / \mathrm{m}[8]$ ), and $R$ is given in (1a) or (2a). It should be noted that (6) does not take into account the hysteretic properties of the soil ionization [10] and the arcing at the earth's surface that further reduce $R$ [11].

The exact model based on the EM field theory (or antenna theory) approach for the computation of ground rod performance at high frequencies was first described in [13], [14] and further developed in [17], [18]. Differences between the transmission line and the EM models are discussed in [13] and comparisons with field measurements are given in [14] and [18]. The exact model is compared with a lumped R-L-C equivalent circuit in [12]. Furthermore in [12], the use of the lumped R-L-C equivalent circuit in Fig. 1(c) is limited to rod lengths of less than one-tenth of the wavelength in soil, which practically limits its use to lower frequencies.

Despite the possibility to use rigorous methods for the analysis of ground rods, there is a need for an accurate equivalent circuit representation that may be used in well-established circuit-based methods or in software for transient and high-frequency analysis of power and communications systems. Such a need is evident in different recent simulation studies, for example, in [15], in the megahertz range and in the emerging power-line communications technology, even up to $50 \mathrm{MHz}$ [16].

One method for evaluating the equivalent circuit parameters was described in [18], [19]: fractional approximation of the impedance frequency functions computed by the EM model. However, in this paper, we look for simpler solutions. We first compare computational results of different methods. In particular, we compare the rigorous full-wave EM-field theory approach with the usual lumped R-L-C and homogenous distributed-parameter circuits. Then we try to synthesize a simple nonhomogenous distributed-parameter circuit that matches the EM model results better by using a simple Matlab-based curve-matching procedure. The interested reader can find a detailed description of the applied EM model in [17] and its validation by comparison with field measurements in [18].

\section{EQuivalent CiRCuIT FREQuenCy RANGE}

Whether the analysis is carried out in the time or frequency domain, the validity of the model can be checked in the frequency domain. For this purpose, it is necessary to determine the frequency range required in the analysis. It should be noted

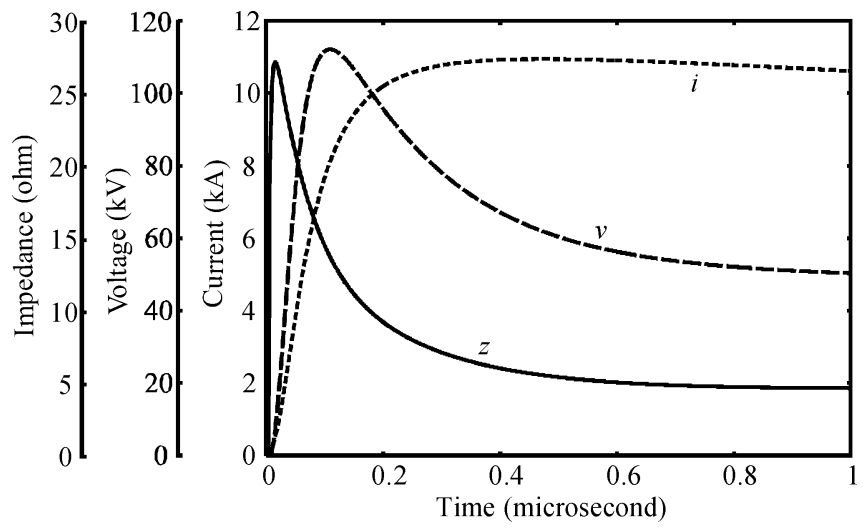

Fig. 2. "Subsequent stroke" current pulse $i$, voltage to remote neutral ground $v$, and impedance to ground $z$ of 6-m ground $\operatorname{rod}$ in soil with $\rho=30 \Omega \mathrm{m}$.

whether the time functions and spectra of the currents and voltages are available in discrete or continuous form; for usual digital computations, the discrete versions of both are required. In such a case, the sampling theorem determines the relation between the highest frequency (or the Nyquist frequency range) $F_{\mathrm{m}}$ and the time sampling rate $\Delta t[21]$

$$
F_{m}=\frac{1}{2 \Delta t} .
$$

In case of lightning, such a frequency range is often determined by the highest appreciable frequency components of the excitation lightning current waves [20]. However, this range should be also determined by the frequency content of the response. For example, usually the sought response is the voltage to ground $v(t)$, which is usually needed for determining the transient impedance to ground, $z(t)$ [20]

$$
z(t)=\frac{v(t)}{i(t)}
$$

Here, $i(t)$ is current injected in the rod.

One example is given in Fig. 2, which shows the simulation results of the EM model [17] for the transient voltage to remote neutral ground at the feed point $v(t)$ and the transient impedance $z(t)$ of a 6-m ground rod in soil with conductivity $\rho=30 \Omega \mathrm{m}$. The ground rod is subjected to a typical "subsequent stroke" current pulse $i(t)$ with a peak value of about $11 \mathrm{kA}$ and a rise time of about $0.2 \mu \mathrm{s}$ (proposed in the IEC Standard [22]).

The transient voltage and impedance in Fig. 2 have a much higher frequency content than the excitation current pulse, and frequency ranges up to $F_{\mathrm{m}}=8 \mathrm{MHz}$ for the voltage and up to $F_{\mathrm{m}}=50 \mathrm{MHz}$ for the impedance were required for reasonable convergence of the results. These frequency ranges $F_{\mathrm{m}}$ correspond to time sample rates of $\Delta \mathrm{t}=0.06 \mu \mathrm{s}$ for the voltage and $\Delta \mathrm{t}=0.01 \mu \mathrm{s}$ for the impedance (both in Fig. 2), which are necessary for evaluating the time functions.

Therefore, the required upper frequency depends largely on the application. In particular, it depends on the parameters of the analyzed case, analyzed quantities, and the accuracy required. It may be below one or above a few megahertz, but it may also be higher than tens of megahertz if fast varying pulses are analyzed.

It should be noted that nonlinear phenomena due to ionization of the soil were not taken into account in the computations in Fig. 2. However, it is worth noting that nonlinear phenomena do 
not have a dominant influence during the rise of the current (for the analyzed case), when the maxima of the transient voltage and impedance occur, since some longer time period is needed for the ionization buildup in the soil [10]. For example, in the analyzed case, the impedance $z(t)$ already settled down to its $\mathrm{dc}$ value at around $0.5 \mu \mathrm{s}$ (Fig. 2). While ionization of the soil may further reduce this value, it will not substantially influence its maximum value.

\section{COMPARISON OF HARMONIC IMPEDANCE TO GROUND COMPUTED BY DIFFERENT APPROACHES}

In this section, we compare the frequency-dependent impedance to ground computed by three different approaches.

The first one is the lumped circuit approach (1) and (2) [Fig. 1(c)]. It is the most approximate one and is based on the assumption that the EM field behaves approximately as a static field. Furthermore, formulas (1) and (2) are derived based on the hypotheses of a uniformly distributed charge and current along the rod and on image theory. Furthermore, $L$ in (2b) is based on the hypothesis of a rod in an infinite uniform medium.

The second approach is the distributed-parameter circuit approach (3) and (4), which assumes transverse-electromagnetic (TEM) propagation on a uniform infinite conductor in a homogeneous medium and neglects the effects of the earth-air interface.

The third one is the EM approach that is based on the least neglects in comparison to more simplified approaches [17], [18]. It follows from a solution of Maxwell's equations for boundary conditions of the EM field at the surface of the conductor and the earth. However, it is still based on some idealistic hypotheses, such as homogeneous earth and ideal contact between the rod and the soil. Additionally it does not take nonlinear phenomena into account.

Unfortunately, there is no available systematically developed and reliable set of experimental data that would serve as a standard, so we consider here the EM model as the basis for comparison.

Fig. 3 shows a comparison of the computed results for the harmonic impedance to ground of short $[\ell=3 \mathrm{~m}$, Fig. 3(a) $]$ and long $[\ell=30 \mathrm{~m}$ Fig. $3(\mathrm{~b})]$ ground rods in more conductive $(\rho=$ $30 \Omega \mathrm{m})$ and in less conductive $(\rho=300 \Omega \mathrm{m})$ soil, computed by the lumped circuit model [Fig. 1(c)], (1) and (2) (designated by "RLC" in Fig. 3], the distributed-parameter circuit model (3) and (4) ("TL" in Fig. 3), and the EM model [17] ("EMF" in Fig. 3). A rod radius of $1.25 \mathrm{~cm}$ and a soil relative permittivity value of 10 is adopted in all computations in this paper.

It may be noted in Fig. 3 that the lumped R-L-C model greatly overestimates the values of impedance to ground at high frequencies. The impedance computed by the R-L-C model is in agreement with the other methods for rod lengths less than approximately one-tenth of the wavelength, which is in agreement with the conclusions in [12]. The model with the distributed-parameter circuit (TL in Fig. 3) follows the EM model better (EMF in Fig. 3), but it still significantly overestimates the values at higher frequencies. Better agreement between results is detained for small rods in very resistive soil $[\ell=3 \mathrm{~m}$ and $\rho=300 \Omega \mathrm{m}$ in Fig. 3(a)].

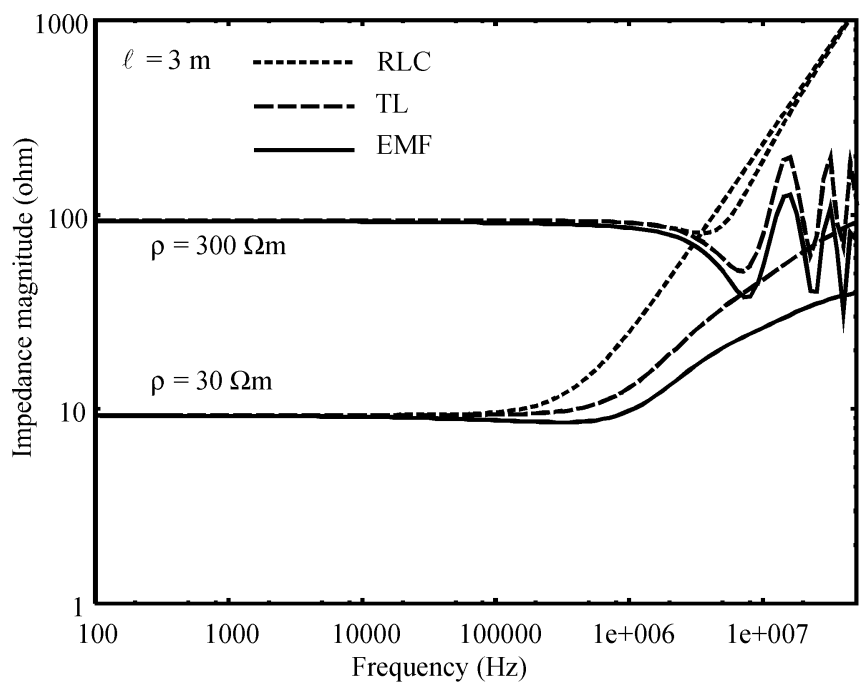

(a)

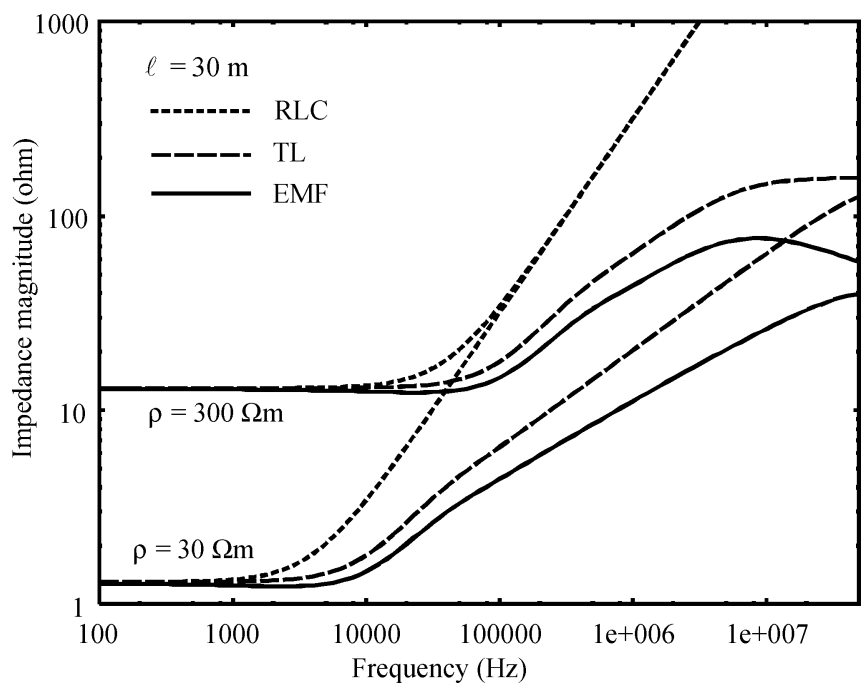

(b)

Fig. 3. Harmonic impedance to ground of (a) short $\ell=3 \mathrm{~m}$ and (b) long $\ell=30-\mathrm{m}$ ground rods in more conductive $(\rho=30 \Omega \mathrm{m})$ and in less conductive $(\rho=300 \Omega \mathrm{m})$ soil.

\section{UNIFORM Distributed EQUIVALENT CIRCUIT}

One possible equivalent circuit that performs better at high frequencies than the lumped R-L-C circuit is a discrete approximation of the uniform distributed-parameter circuit Fig. 1(d). It consists of $N$ R-L-C sections with the parameters given in (5). One question is how to determine the number of sections $N$ in the circuit.

For $N=1$, the equivalent circuit is equal to the lumped R-L-C circuit Fig. 1(c) and for $N \rightarrow \infty$, it converges to the distributed parameter circuit in (3) and (4). So, for any number of segments, the results will be found between these two models (in Fig. 3, between the dotted line-the lumped RLC circuit, and the broken line-the distributed parameter circuit). Consequently, the results can be improved by choosing a larger $N$ (i.e., by adding more sections to the circuit). However, it should be emphasized that too complex circuits may not be justified if one takes into account the uncertainty and the influence of the underlying assumptions, such as homogenous soil, which might not be valid in reality. 

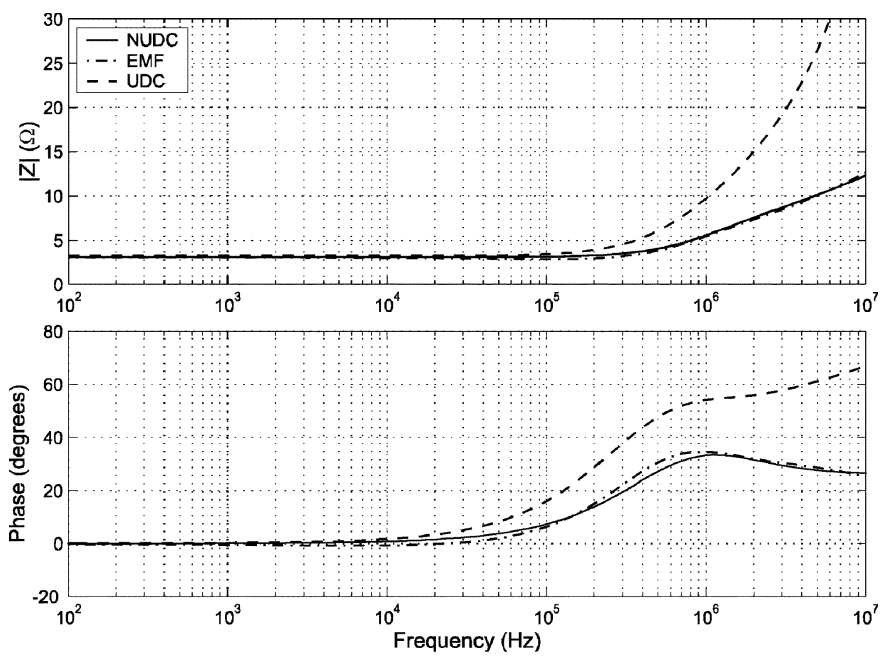

(a)
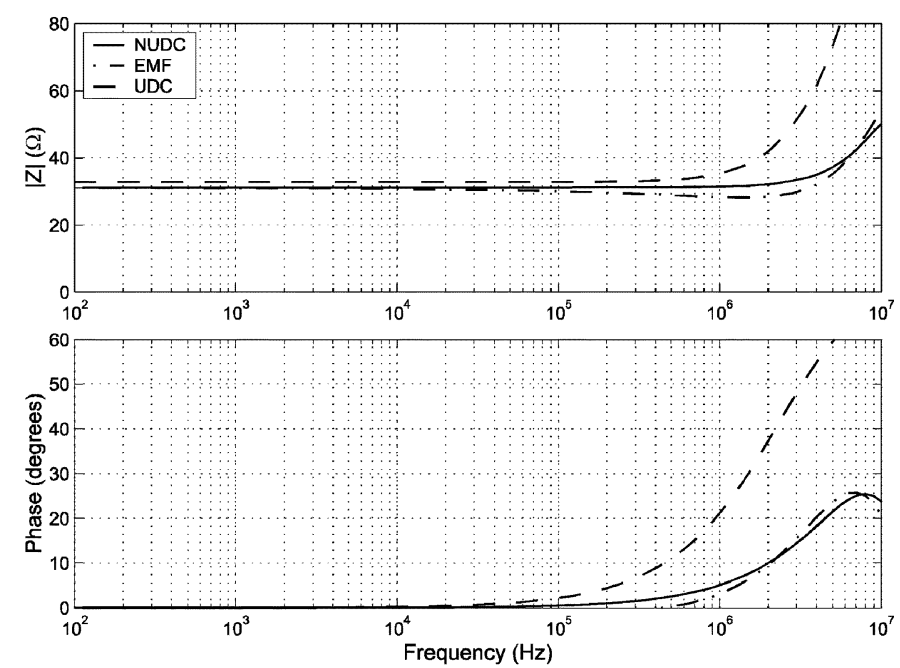

(b)
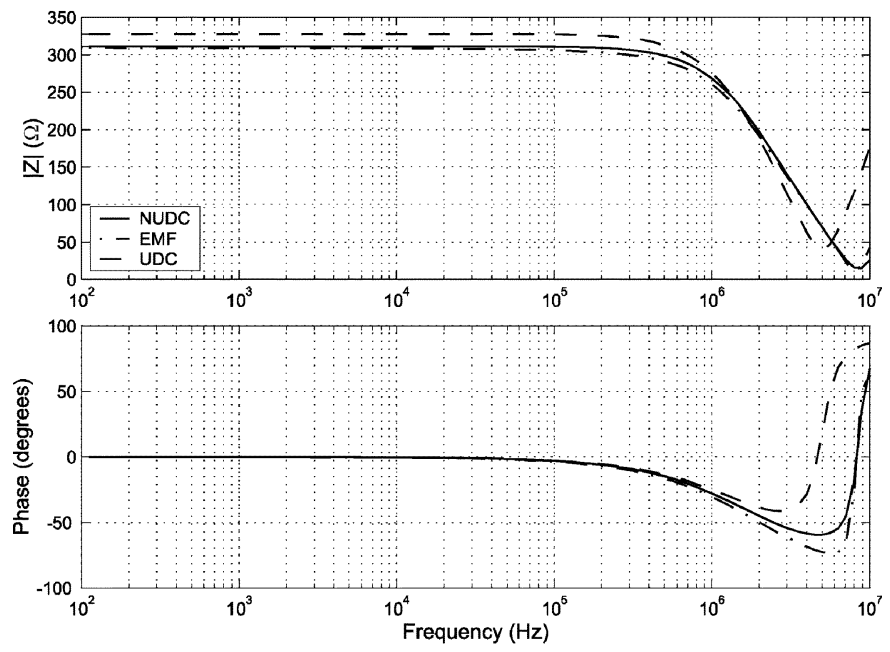

(c)

Fig. 4. Harmonic impedance amplitude (upper trace) and phase (lower trace) of a 3-m rod in a soil with different $\rho$. (a) $10 \Omega \mathrm{m}$. (b) $100 \Omega \mathrm{m}$. (c) $1000 \Omega \mathrm{m}$.

Results of computations are shown in Figs. 4 and 5 (dashed line denoted by "UDC"). The parameters are computed by (2)
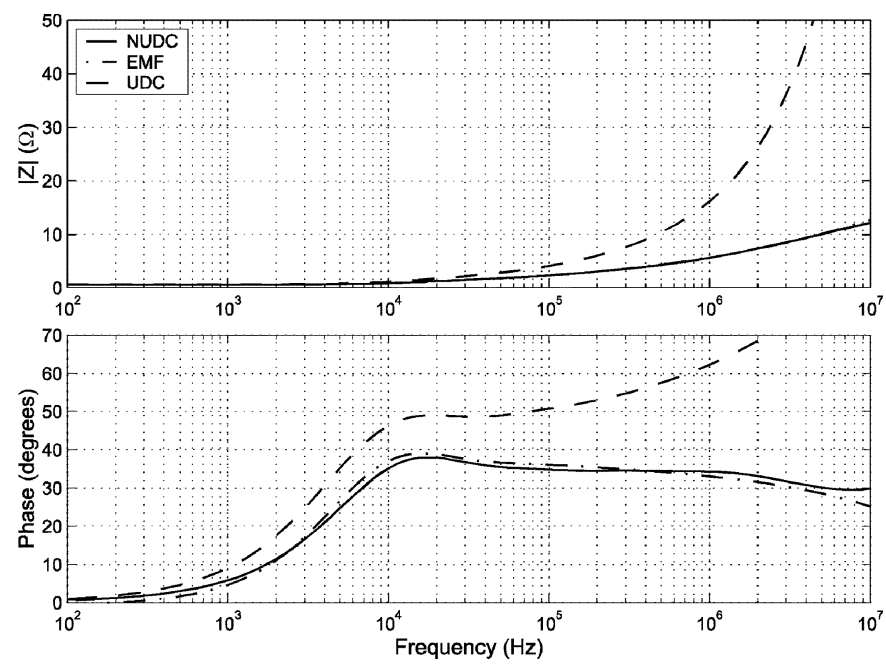

(a)
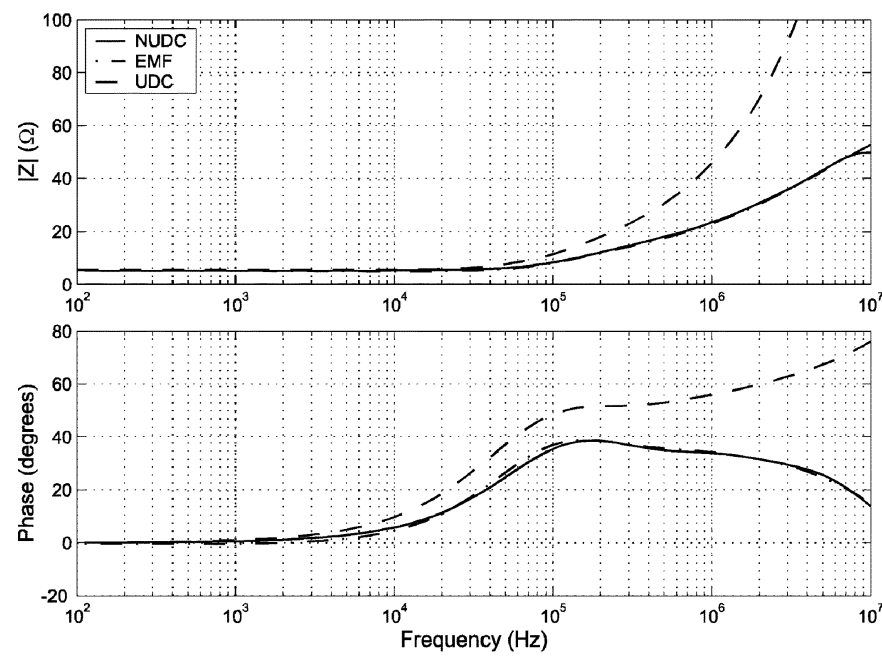

(b)
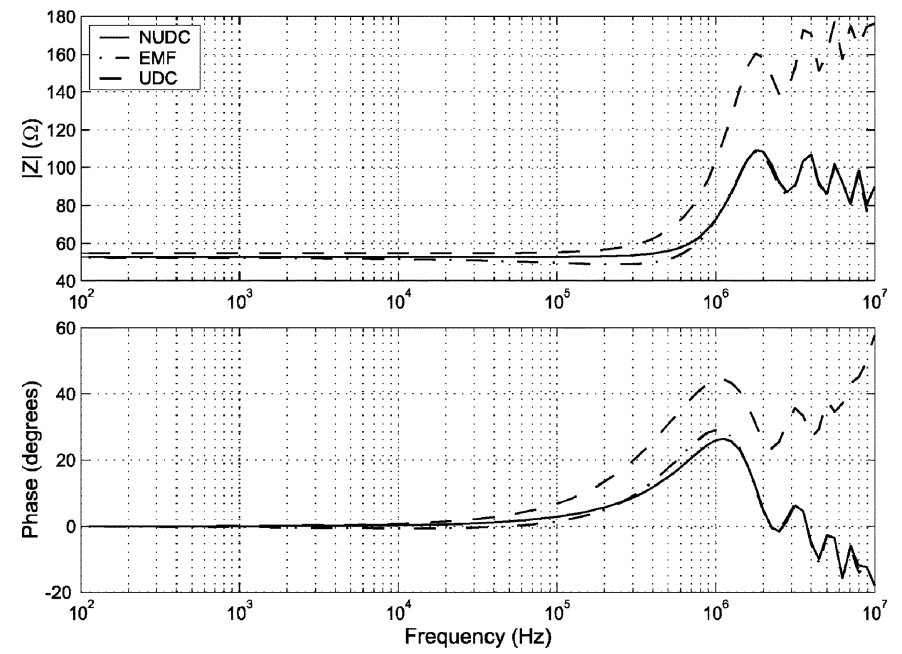

(c)

Fig. 5. Harmonic impedance amplitude (upper trace) and phase (lower trace) of a $24-\mathrm{m}$ rod in a soil with different $\rho$. (a) $10 \Omega \mathrm{m}$. (b) $100 \Omega \mathrm{m}$. (c) $1000 \Omega \mathrm{m}$.

and the number of sections, for comparison reasons, is chosen to be the same as in the nonuniform distributed circuit, described in the next section. 


\section{NONUNIFORM DISTRIBUTED EQUIVALENT CIRCUIT}

Further improvement of the results is possible by a nonuniform distributed circuit. We found that a simple modification of the uniform distributed circuit may lead to a better match of the impedance to ground obtained by the EM model. For this purpose, only the values of $L_{n}$ for the inductors are modified in each section, while for the resistors and capacitors, the values are identical (it has been found that modification of their values did not improve the results). The values of $R_{n}$ are matched to the low-frequency values of the impedance to ground computed by the EM model, and $C_{n}$ the same as in (5). The values of $L_{n}$ may be determined by the following simple curve-matching procedure.

The procedure starts with a single R-L-C segment, where values of $R_{n}$ and $C_{n}$ are fixed, and the program searches only for the $L_{n}$ element that gives the best curve matching with the impedance to ground given by the EM model. For this, the Matlab's Minimize Function of Several Variables (FMINS) function [24] was used. If a reasonably accurate matching over the whole frequency range could not be found, then the number of sections were increased and the program had to search for new values of $L_{n}$ in all sections. This process was continued until reasonable convergence of the results was achieved. It should be pointed out that the solution is not unique. The more sections that are used, the more different inductances can be found which satisfy the given impedance and phase characteristic.

Figs. 4 and 5 show harmonic impedances to ground computed by the EM model and the equivalent circuits (the EM model with the dash-point line denoted by "EMF," the nonuniform distributed circuit with solid line denoted by "NUDC," and the uniform distributed circuit with the dashed line denoted by "UDC"). For completeness, Tables I and II in the Appendix give the parameters $R_{n}, C_{n}$, and $L_{n}$ that are used in the computation of the nonuniform distributed circuit results in Figs. 4 and 5.

The drawback of this procedure is that the specific choice of parameters $L_{n}$ is not physically based, and optimization of any ground rod requires utilization of the EM model. However, this procedure offers a simple interface between the ground rod EM model and power system circuit models. It provides an equivalent circuit for single ground rods when overestimation of the results by the homogeneous distributed circuit is considered unacceptable.

The nonlinear behavior of ground rod resistance in case of high lightning currents may be modeled by nonlinear resistances $R_{n}(t)$ (6) (as suggested in [8]) in the sections of the equivalent circuit, similar to [15].

\section{CONCLUSION}

A comparison between three models for frequency-dependent simulation of a ground rod: the lumped R-L-C circuit, the distributed-parameter circuit, and the EM model show significant differences at high frequencies.

The application of the lumped circuit R-L-C model is limited to cases where the length of the rod is less than one-tenth of the wavelength in earth. This practically limits the frequency range of the validity of this model to some lower frequencies,
TABLE I

EQUIVALENT CIRCUIT INDUCTANCES USED IN COMPUTATIONS IN FIGS. 4 AND 5

\begin{tabular}{|c|c|c|c|c|c|c|}
\hline \multirow[t]{2}{*}{$(\mu \mathrm{H})$} & \multicolumn{2}{|c|}{$\rho=10 \Omega \mathrm{m}$} & \multicolumn{2}{|c|}{$\rho=100 \Omega \mathrm{m}$} & \multicolumn{2}{|c|}{$\rho=1000 \Omega \mathrm{m}$} \\
\hline & $3 \mathrm{~m}$ & $24 \mathrm{~m}$ & $3 \mathrm{~m}$ & $24 \mathrm{~m}$ & $3 \mathrm{~m}$ & $24 \mathrm{~m}$ \\
\hline $\mathrm{L}_{1}$ & 0.61 & 1.86 & 1.651 & 2.207 & 1.234 & 1.921 \\
\hline $\mathrm{L}_{2}$ & 0.747 & 2.56 & 0.305 & 0.168 & & 6.728 \\
\hline $\mathrm{L}_{3}$ & 0.216 & 0.079 & & 0.530 & & 4.364 \\
\hline $\mathrm{L}_{4}$ & 0.580 & 0.006 & & 4.814 & & 4.406 \\
\hline $\mathrm{L}_{5}$ & 0.402 & 0.272 & & 1.915 & & 3.952 \\
\hline $\mathrm{L}_{6}$ & 0.156 & 1.843 & & 7.134 & & 3.470 \\
\hline $\mathrm{L}_{7}$ & 0.017 & 0.051 & & 0.071 & & 3.150 \\
\hline $\mathrm{L}_{8}$ & & 0.531 & & 4.301 & & 2.590 \\
\hline $\mathrm{L}_{9}$ & & 3.254 & & 1.912 & & 1.996 \\
\hline $\mathrm{L}_{10}$ & & 7.205 & & 1.855 & & 0.364 \\
\hline $\mathrm{L}_{11}$ & & 0.054 & & 0.264 & & \\
\hline $\mathrm{L}_{12}$ & & 0.017 & & & & \\
\hline $\mathrm{L}_{13}$ & & 0.031 & & & & \\
\hline $\mathrm{L}_{14}$ & & 1.080 & & & & \\
\hline $\mathrm{L}_{15}$ & & 4.203 & & & & \\
\hline $\mathrm{L}_{16}$ & & 0.273 & & & & \\
\hline $\mathrm{L}_{17}$ & & 1.705 & & & & \\
\hline $\mathrm{L}_{18}$ & & 0.841 & & & & \\
\hline $\mathrm{L}_{19}$ & & 1.563 & & & & \\
\hline $\mathrm{L}_{20}$ & & 0.728 & & & & \\
\hline $\mathrm{L}_{21}$ & & 0.687 & & & & \\
\hline $\mathrm{L}_{22}$ & & 0.566 & & & & \\
\hline $\mathrm{L}_{23}$ & & 0.051 & & & & \\
\hline
\end{tabular}

TABLE II

EQUIVALENT CIRCUIT RESISTANCES AND CAPACITANCES USED IN COMPUTATIONS IN FIGS. 4 AND 5

\begin{tabular}{ccccccc}
\hline & \multicolumn{3}{c}{$\mathrm{R}_{\mathrm{n}}(\Omega)$} & \multicolumn{3}{c}{$\mathrm{C}_{\mathrm{n}}(\mathrm{nF})$} \\
\hline & & \multicolumn{2}{c}{$\rho(\Omega \mathrm{m})$} \\
\hline $3 \mathrm{~m}$ & 21.85 & 30.90 & 311.4 & 0.041 & 0.284 & 0.284 \\
$24 \mathrm{~m}$ & 12.12 & 57.86 & 527.0 & 0.007 & 0.152 & 0.168 \\
\hline
\end{tabular}

depending on the EM properties of the soil and length of the rod. At frequencies higher than this limit, the model greatly overestimates the impedance to ground.

The distributed parameter circuit model fits the EM model better, but it still overestimates the values at higher frequencies. Better agreement between results is only obtained for small rods in very resistive soil.

Two equivalent circuits have been compared: the first one approximates the distributed-parameter circuit model and the second one approximates the EM model. The latter is a nonuniform discrete distributed circuit whose parameters are obtained by curve matching of the EM model. A simple Matlab-based curve-matching procedure has been described. Such equivalent circuit also provides a simple interface between the ground rod EM model and usual circuit-based methods for power system analysis.

Concerning the practical application of the described equivalent circuits, the following conclusions can be drawn. 
- The lumped R-L-C circuit can be used in its validity domain or for the preliminary analysis, with the knowledge that it might greatly overestimate the ground rod impedance at high frequencies.

- The discrete approximate distributed-parameter circuit reduces the overestimation of the ground rod impedance at high frequencies in comparison with the lumped R-L-C circuit. One should also check the sensitivity of the overall results to this change.

- If further reduction of the overestimation of the impedance to ground at high frequencies is needed, the EM model might be used. Equivalent circuit parameters can be determined by the described curve matching procedure.

\section{APPENDIX}

\section{PARAMETERS OF THE NONUNIFORM DISTRIBUTED CIRCUITS USED IN COMPUTATIONS}

Table I contains data for the inductances and Table II is for the resistances and the capacitances in the equivalent circuits used for the computations in Figs. 4 and 5.

\section{ACKNOWLEDGMENT}

The authors wish to express their thanks to Dr. A. P. J. van Deursen, Dr. F. Tesche, Dr. F. Rachidi, Prof. V. Rakov, and especially Prof. R. Olsen, whose comments and suggestions allowed us to improve the manuscript.

\section{REFERENCES}

[1] P. Hasse and J. Wiesinger, Handbook for Lightning and Grounding (in German), 4th ed. Munich, Germany: Pflaum, 1993

[2] G. F. Tagg, Earth Resistances. London, U.K.: Newnes, 1964.

[3] E. F. Vance, Coupling to Shielded Cables. New York: Wiley, 1978.

[4] F. M. Tesche, M. V. Ianoz, and T. Karlsson, EMC Analysis Methods and Computational Models. New York: Wiley, 1997.

[5] R. Rudenberg, Electrical Shock Waves in Power Systems. Cambridge, MA: Harvard Univ. Press, 1968.

[6] E. D. Sunde, Earth Conduction Effects in Transmission Systems. New York: Van Nostrand, 1949.

[7] S. Bourg, B. Sacepe, and T. Debu, "Deep earth electrodes in highly resistive ground: Frequency behavior," in Proc. IEEE Int. Symp. Electromagnetic Compatibility, 1995, pp. 584-589.

[8] A. F. Imece, D. W. Durbak, H. Elahi, S. Kolluri, A. Lux, D. Mader, T. E. McDermott, A. Morched, A. M. Mousa, R. Natarajan, L. Rugeles, and E. Tarasiewicz, "Modeling guidelines for fast front transients," IEEE Trans. Power Del., vol. 11, no. 1, pp. 493-506, Jan. 1996.

[9] L. P. Kalantarov and L. A. Ceitlin, Inductance Calculation (in Russian). Leningrad: Energoatomizdat, 1986.

[10] A. C. Liew and M. Darveniza, "Dynamic model of impulse characteristics of concentrated earths," Proc. Inst. Elect. Eng., vol. 121, pp. 123-135, February 1974

[11] V. A. Rakov, M. A. Uman, K. J. Rambo, M. I. Fernandez, R. J. Fisher, G. H. Schenetzer, R. Tottappillil, A. Eybert-Berard, J. P. Berlandis, P. Lalande, A. Bonamy, P. Laroche, and A. Bondiou-Clergerie, "New insights into lightning processes gained from triggered-lightning experiments in Florida and Alabama," J. Geophys. Res., pp. 14,117-14 130, 1998.

[12] R. G. Olsen and M. C. Willis, "A comparison of exact and quasistatic methods for evaluating grounding systems at high frequencies," IEEE Trans. Power Del., vol. 11, no. 2, pp. 1071-1081, Apr. 1996.

[13] J. P. Plumey, D. Roubertou, J. Fontaine, and P. Kouteynikoff, "High frequency harmonic input impedance of an antenna embedded in a conducting half-space," in Proc. Int. Zurich Symp. Electromagnetic Compatibility, 1983, pp. 45-50.
[14] D. Roubertou, J. Fontaine, J. P. Plumey, and A. Zeddam, "Harmonic input impedance of earth connections," in Proc. IEEE Int. Symp. Electromagnetic Compatibility, 1984, pp. 717-720.

[15] C. T. Mata, M. I. Fernandez, V. A. Rakov, and M. A. Uman, "EMTP modeling of a triggered-lightning strike to the phase conductor of an overhead distribution line," IEEE Trans. Power Del., vol. 15, no. 4, pp. $1175-1181$, Oct. 2000

[16] F. M. Tesche, B. A. Renz, R. M. Hayes, and R. G. Olsen, "Development and use of a multiconductor line model for PLC assessments," in Proc. Int. Zurich Symp. Electromagnetic Compatibility, 2003, pp. 99-104.

[17] L. Grcev and F. Dawalibi, "An electromagnetic model for transients in grounding systems," IEEE Trans. Power Del., vol. 5, no. 4, pp. 1773-1781, Oct. 1990.

[18] L. Grcev, "Computer analysis of transient voltages in large grounding systems," IEEE Trans. Power Del., vol. 11, no. 2, pp. 815-823, Apr. 1996.

[19] M. Heimbach, "Simulation of complex-valued, frequency-dependent quantities in transients programs," Eur. Trans. Elect. Power, vol. 7, pp. 381-388, Nov./Dec. 1997.

[20] C. Mazzetti and G. M. Veca, "Impulse behavior of ground electrodes," IEEE Trans. Power App. Syst., vol. PAS-102, no. 9, pp. 3148-3156, Sep. 1983.

[21] E. O. Brigham, The Fast Fourier Transform. Upper Saddle River, NJ: Prentice-Hall, 1974.

[22] Protection Against Lightning Electromagnetic Impulse. Part 1: General Principles, IEC Int. Std. 1312-1, IEC, Geneva, Switzerland, 1995.

[23] TRAGSYS-Software for High Frequency and Transient Analysis of Grounding Systems. [Online] Available: http://tragsys.com

[24] MATLAB. [Online]http://www.mathworks.com

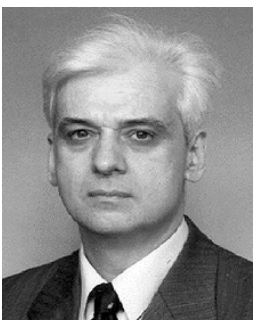

Leonid Grcev (M'84-SM'97) was born in Skopje, Macedonia, in 1951. He received the Dipl.-Ing. degree in electrical engineering from the St. Cyril and Methodius University, Skopje, in 1978 and the M.S. and Ph.D. degrees in electrical engineering from the University of Zagreb, Zagreb, Croatia, in 1982 and 1986, respectively.

Currently, he is Full Professor with the Faculty of Electrical Engineering at the St. Cyril and Methodius University, where he has also been Assistant Professor, Associate Professor, and Vice Dean since 1988. From 1978 to 1988 , he was with the Electric Power Company of Macedonia, Skopje, working in the Telecommunications Department. He has been a Visiting Professor at the Technical University of Aachen, Aachen, Germany, the Eindhoven University of Technology, Eindhoven, The Netherlands; and the Swiss Federal Institute of Technology, Lausanne, Switzerland. He was responsible for several international projects related to EMC. His research interests include EMC of power systems and modeling of grounding systems and connected structures at high frequencies and transients with particular reference to lightning. He is author and coauthor of many scientific papers published in reviewed journals and presented at international conferences.

Dr. Grcev is a member of the CIGRE Working Group C4.04 (General Aspects of EMC and EMF) and has been Chairperson and a member of scientific committees at international conferences.

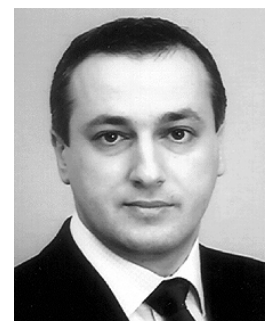

Marjan Popov (M'95-SM'03) was born in Kavadarci, Macedonia, in 1969. He received the Dipl.-Ing. and M.S. degrees in electrical engineering from the St. Cyril and Methodius University, Skopje, Macedonia, in 1993 and 1998, respectively, and the Ph.D. degree from Delft University of Technology (TU Delft), Delft, The Netherlands, in 2002.

Currently, he is an Assistant Professor with the Power System Laboratory at TU Delft. In 1997, he was an Academic Visitor at the University of Liverpool, Liverpool, U.K. His fields of interest are arc modeling, transients in power systems, parameter estimation and relay protection.

Dr. Popov is a current member of the Dutch CIGRE SC 34 and was a Secretary of the Macedonian CIGRE B5: Relay Protection. 